\title{
Previsão de escorregamentos no município de Maceió (AL) a partir do modelo AHP
}

\section{Landslides prediction in Maceió city (AL) from AHP model}

\author{
Carlos de Oliveira Bispo" ${ }^{1 *}\left(\right.$ (D) , Fabrizio de Luiz Rosito Listo ${ }^{1} \square$ (D), Nivaneide Alves de Melo \\ Falcão ${ }^{2} \bowtie(\mathbb{D}$, Danielle Gomes da Silva Listo $₫(\mathbb{D}$
}

\author{
1 Departamento de Ciências Geográficas, Centro de Filosofia e Ciências Humanas, Universidade \\ Federal de Pernambuco, Recife, Pernambuco, Brasil \\ 2 Instituto de Geografia, Desenvolvimento e Meio Ambiente, Universidade Federal de Alagoas, \\ Maceió, Alagoas, Brasil \\ E-mails: fabriziolisto@gmail.com (FLRL); nivaneide.ufal@yahoo.com.br (NAMF); \\ dannyavlis@yahoo.com.br (DGSL) \\ *E-mail para correspondência: bispocarlos93@gmail.com
}

Recebido (Received): 23/08/2019 Aceito (Accepted):16/03/2020

\begin{abstract}
Resumo: A previsão de escorregamentos é bastante relevante para o planejamento territorial, na medida que indica os locais com maior probabilidade de serem atingidos por estes processos. Dessa forma, o objetivo deste trabalho é avaliar a suscetibilidade a escorregamentos no litoral norte de Maceió, Nordeste do Brasil, por meio do modelo AHP (Analytic Hierarchy Process) em ambiente SIG (Sistemas de Informação Geográfica). Na hierarquização do modelo foram utilizados parâmetros relativos à geologia, à geomorfologia, aos solos, à declividade e à forma da encosta. A análise espacial foi realizada por meio de métodos multicritérios e álgebra de mapas com a ponderação das variáveis via AHP. Para a validação dos resultados, foi utilizado um mapa de inventário com 29 cicatrizes de escorregamentos mapeadas do ano de 2017. Os resultados mostraram que o mapa de suscetibilidade apresentou um predomínio da classe de suscetibilidade média, ou seja, com médio potencial para ocorrência de escorregamentos. Nesse sentido, as classes de suscetibilidade baixa, média e alta, apresentaram, respectivamente, uma frequência de $26 \%, 64 \%$ e $10 \%$. Ao validar os resultados, $69 \%$ das cicatrizes de escorregamentos concentraram-se na classe de suscetibilidade alta; $30 \%$ na classe de suscetibilidade média e, apenas, $1 \%$ na classe de suscetibilidade baixa, indicando sucesso na previsão realizada. Os mapeamentos indicaram que os locais mais suscetíveis a escorregamentos se situam nas áreas de encostas, principalmente quando correlacionadas com a forte influência da declividade e dos padrões côncavos do terreno.
\end{abstract}

Palavras-chave: Geomorfologia; Suscetibilidade; Escorregamentos; AHP; Nordeste brasileiro.

Abstract: The prediction of landslides is very relevant for territorial planning, as it indicates the places most likely to be affected by these processes. Thus, the objective of this work is to assess the susceptibility to landslides on the north coast of Maceió, Northeast Brazil, using the AHP model (Analytic Hierarchy Process) in a GIS environment (Geographic Information Systems). In the hierarchy of the model, parameters related to geology, geomorphology, soils, slope and slope shape were used. Spatial analysis was performed using multicriteria methods and map algebra with the weighting of variables via AHP. For the validation of the results, an inventory map with 29 landslide scars mapped from the year 2017 was used. The results showed that the susceptibility map had a predominance of the average susceptibility class, that is, with medium potential for the occurrence of landslides. In this sense, the classes of low, medium and high susceptibility, presented, respectively, a frequency of $26 \%, 64 \%$ and $10 \%$. When validating the results, $69 \%$ of the slip scars were concentrated in the high susceptibility class; $30 \%$ in the medium susceptibility class and only $1 \%$ in the low susceptibility class, indicating success in the forecast made. The mappings indicate that the places most susceptible to landslides are located in the slope areas, especially when correlated with the strong influence of the slope and the concave patterns of the terrain.

Keywords: Geomorphology; Susceptibility; Landslides; AHP; Brazilian Northeast. 


\section{Introdução}

Os escorregamentos, em linhas gerais, são movimentos rápidos de curta duração, com velocidades que variam de metros por hora a metros por segundo. Apresentam planos de ruptura bem definidos entre o material deslizado e o não movimentado (GUIDICINI; NIEBLE, 1984; SELBY, 1993; AUGUSTO FILHO 1992; GUERRA et al., 2017), e podem assumir geometria rotacional, translacional ou em formato de cunha.

Diversos parâmetros naturais condicionam a deflagração de escorregamentos, tal como, o tipo de solo, a geologia, a forma do terreno, a declividade, a pluviometria, entre outros (GUIDICINI e NIEBLE, 1984). Assim, o conceito de suscetibilidade indica a potencialidade de ocorrência de processos naturais em uma dada área, expressando-se segundo classes de probabilidade, ou ainda, propensão ao desenvolvimento do processo em uma dada área (BRASIL, 2007; PFALTZGRAFF 2007; FEEL et al., 2008; BRITO, 2014; TORRES 2014).

O mapeamento da suscetibilidade a escorregamentos constitui-se como uma ferramenta técnica-científica de planejamento urbano, servindo como aporte para gestores públicos anteciparem-se quanto a possíveis problemas em áreas ocupadas ou em consolidação. Ademais, esse tipo de mapeamento é de baixo custo e de alta eficiência, minimizando perdas sociais, econômicas e vítimas (FELL et al., 2008).

Conforme Pfaltgraff (2007), a carta de suscetibilidade visa indicar as áreas com características naturais que necessitem de maior atenção e laudos técnicos para ocupação ou preservação. Dessa forma, possibilita à gestão pública, por exemplo, informações relevantes para a implantação de novos loteamentos, conjuntos habitacionais, estradas e demais obras de infraestrutura.

O modelo AHP (Analytic Hierarchy Process), desenvolvido por Saaty (1991), calcula a probabilidade de escorregamentos por meio da análise multicritério, na qual a partir de uma base matemática, organiza e avalia a importância relativa e hierarquizada de fatores condicionantes dos processos, checando-se a consistência dos pesos atribuídos (SAATY, 1991). O modelo vem sendo amplamente utilizado nacionalmente e internacionalmente apresentando resultados com excelente precisão.

No Brasil, Brito (2014) aplicou o modelo no município de Porto Alegre - RS, frequentemente atingida por escorregamentos. Torres (2014) e Menezes Júnior (2015) aplicaram o modelo nas paisagens úmidas nordestinas, nos municípios pernambucanos de Ipojuca e Paulista, respectivamente.

Internacionalmente, Tran et al. (2002) aplicaram o modelo para avaliar a vulnerabilidade ambiental na região do Médio Atlântico nos Estados Unidos. Reis et al. (2012) executaram a AHP em um estudo sobre a suscetibilidade a escorregamentos na região nordeste da Turquia. Shahabi et al. (2014) aplicaram o modelo em uma das províncias do Irã (Azerbaijão Ocidental).

Nesse cenário, o objetivo deste trabalho é avaliar a suscetibilidade a escorregamentos no litoral norte de Maceió, Nordeste do Brasil, por meio da aplicação do modelo AHP em ambiente SIG (Sistemas de Informação Geográfica). A seleção da área de estudo justifica-se devido a ocorrência de escorregamentos na região, cuja ocupação urbana está aumentando devido práticas de especulação imobiliária.

\section{2. Área de estudo}

O município de Maceió localiza-se na faixa costeira do nordeste oriental, com área de, aproximadamente, $503 \mathrm{~km}^{2}$ e população estimada de 1.012 .382 habitantes (IBGE, 2018). O perímetro urbano municipal é dividido, oficialmente, em 50 bairros (Lei mun. 4952/2000) constituindo-se por oito Regiões Administrativas - RA. A área estudada insere-se na Região Administrativa 8 (RA-8), ao litoral norte do município, amplamente atingida por escorregamentos sobretudo do tipo translacional raso (Figura 1).

A morfologia do relevo em Maceió é condicionada pelo tectonismo tardio da Bacia Sedimentar de Alagoas, pelas oscilações climáticas regionais e pelas variações eustáticas quaternárias (MACEIÓ,2007a), cujos principais compartimentos morfogenéticos são: os Tabuleiros (Planalto Sedimentar Litorâneo), as Planícies Flúvio-Lagunares e a Planície Marinha. O relevo apresenta predomínio de terras baixas com altitudes inferiores a 100 metros. As encostas encaixadas nos tabuleiros formam vales em "V", cuja amplitude (vertical) varia entre $40 \mathrm{~m}$ e $60 \mathrm{~m}$, entrecortadas e dissecadas por cursos hidrográficos que desaguam no oceano (COSTA; RAMOS, 2004). 

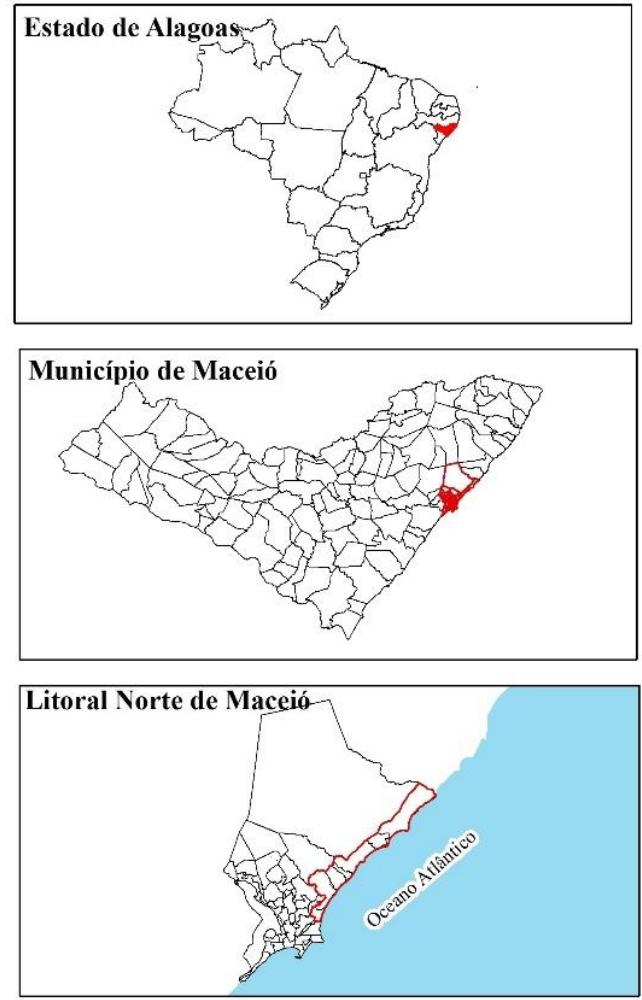

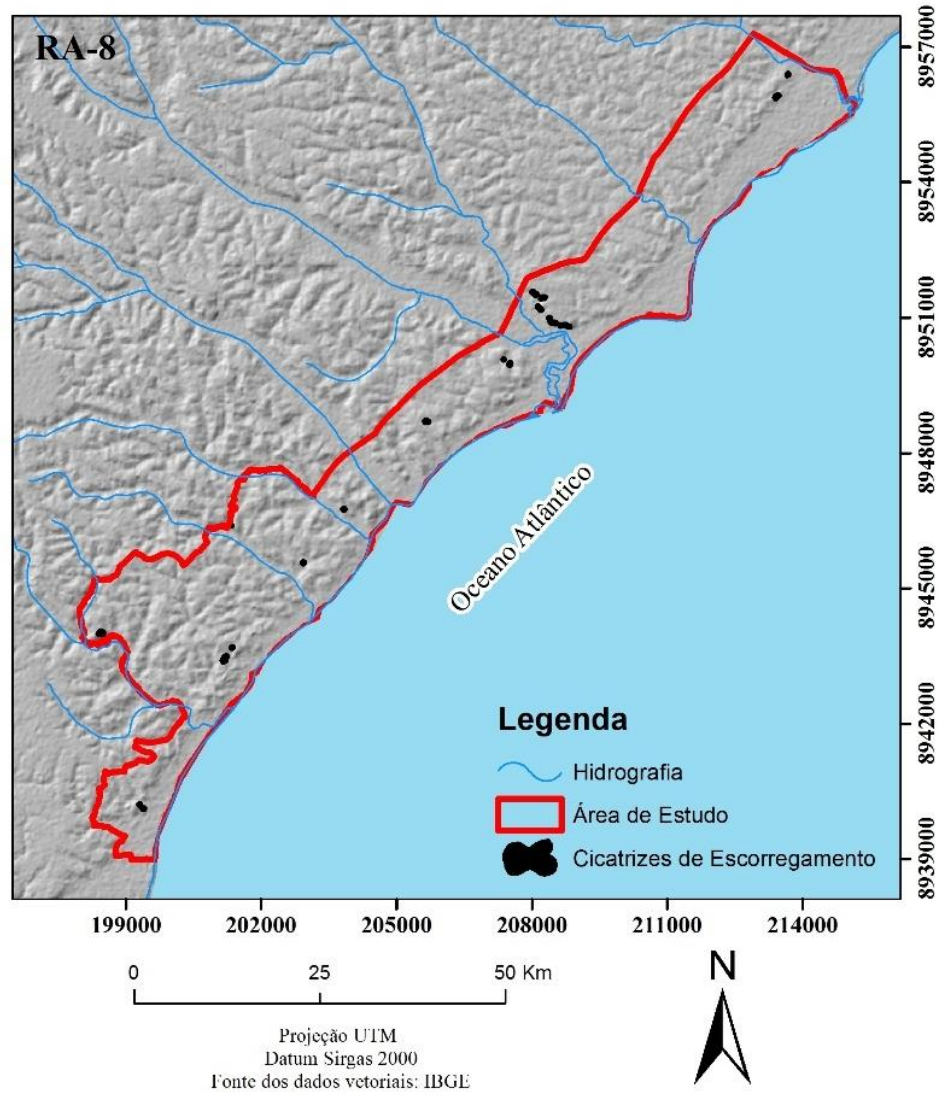

lonte dos dados vetoriais: $\mathrm{BBG}$

Figura 1: Localização da área de estudo e inventário de cicatrizes de escorregamentos mapeados em 2017. Fonte: Autoria própria (2020)

Os litotipos predominantes são da Formação Barreiras, essencialmente compostos por sedimentos pouco ou mal consolidados, depósitos de areias grossas, intercaladas por estratos rítmicos de areia fina e/ou argila. Estas possuem características granulométricas e mineralógicas bastante friáveis, favorecendo a deflagração de escorregamentos (MACEIÓ, 2007a; PFALTZGRAFF, 2007). Pedologicamente, ocorrem Gleissolos, Argissolos, Latossolos e Neossolos. Destes, os argissolos e os latossolos são condicionantes significativos para elevar o grau de suscetibilidade a escorregamentos, devido a suas estruturas internas (RODRIGUES, CALHEIROS; MELO, 2007).

O clima de Maceió é quente e úmido com pluviometria anual média de $1.800 \mathrm{~mm}$. Entre os principais sistemas sinóticos atuantes destacam-se, a Zona de Convergência Intertropical (ZCIT); os sistemas Frontais (SF); as ondas de Leste; os Ventos Alísios de Nordeste e de Sudeste e as brisas (SOUZA, et.al., 1998; MOLION; BERNADO, 2002). O período de maior índice pluviométrico (quadra chuvosa) ocorre entre abriljulho, devido ao deslocamento da Zona de Convergência do ENE (ZCEN), fomentada pela convergência de umidade dos Alísios com a brisa terrestre (SOUZA, et.al., 1998; MOLION e BERNADO 2002).

É justamente no período chuvoso que acontece a maior deflagração de escorregamentos, em função das taxas de infiltração de água no solo, que ao percolarem desestabilizam as encostas (Figura 2). Nesse sentido, conforme Camarinha, Canavesi e Alvalá (2014), a elevada quantidade de chuva em áreas suscetíveis, como por exemplo, encostas íngremes desmatadas, descontinuidades litológicas e pedológicas, entre outros, associadas a assentamentos precários sem infraestrutura favorecem a ruptura do terreno. 


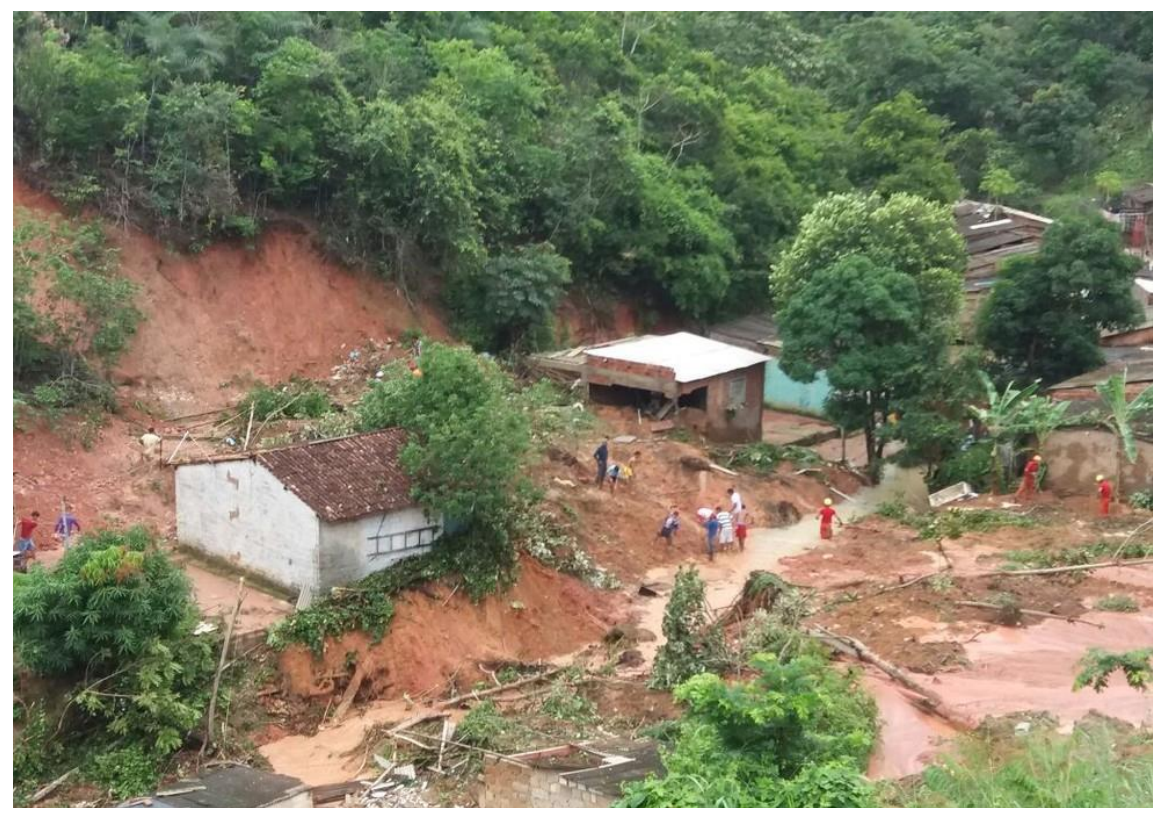

Figura 2: Escorregamento translacional ocorrido no município de Maceió em 2017. Fonte: G1/AL (2017)

\section{Material e Métodos}

\subsection{Seleção dos parâmetros (modelo AHP)}

Os parâmetros selecionados para a geração do cenário de suscetibilidade por meio do modelo AHP foram: declividade, formas da encosta e geomorfologia em escala 1:50.000 e geologia e solos, em escala 1:100.000. Os mapas de declividade, de formas da encosta e de geomorfologia foram gerados por meio de um Modelo Digital do Terreno (MDT) a partir de dados disponibilizados, gratuitamente, pelo satélite ALOS (Advanced Land Observing Satellite) S PALSAR (Phased Array type L-band Synthetic Aperture Radar). O MDT final apresentou resolução de $12,5 \mathrm{~m}$, sendo elaborado por meio de uma rotina automatizada em ambiente SIG.

Para a classificação do mapa de declividade foram adotados três intervalos $\left(0^{\circ} \mathrm{e} 9,6^{\circ} ; 9,7^{\circ} \mathrm{e} 16,7^{\circ} ; 16,8^{\circ}>\right)$, das quais, quanto maior o grau de declividade, maior a suscetibilidade aos escorregamentos. Tais classes estão de acordo com a Lei Lehmann, Lei Federal n.6.766/79, cuja ocupação é permitida nas duas primeiras classes e na terceira, não é permitida, salvo se atendidas exigências legais e técnicas de autoridades competentes. O mapa de formas da encosta seguiu a proposta metodológica de Valeriano e Carvalho Júnior (2003), considerando os seguintes conjuntos de formas: retilínea/planar; convexo/planar; côncavo/planar; côncavo/divergente; convexo/divergente; retilínea/divergente; retilínea/convergente; convexo/divergente e convexo/convergente. Conforme Valeriano e Carvalho (2003) as formas côncavas são as que mais favorecem à deflagração de escorregamentos devido ao acúmulo de fluxos hídricos.

Para o mapa de Unidades Geomorfológicas foram utilizados os critérios do Manual Técnico de Geomorfologia do Instituto Brasileiro de Geografia e Estatística (IBGE, 2009). O mapeamento foi realizado a partir de dados topográficos adquiridos pelo MDT supracitado (ALOS PALSAR) para extração da declividade, da altimetria e das curvas de nível, juntamente com litologia, solo, imagens de satélite (RapidEye, Google Earth Pro) e levantamentos de campo, essenciais para compreender a complexidade de formas existentes na área estudada. Os procedimentos foram realizados em ambiente SIG visando-se obter os compartimentos geomorfológicos da área.

O mapa de Solos (1:100.000) foi compilado da Empresa Brasileira de Pesquisa Agropecuária (Embrapa, 2012) e o mapa de unidades geológicas (1:100.000) provém do mapeamento realizado em Alagoas pela Companhia de Pesquisa de Recursos Minerais (CPRM, 2014).

\subsection{Graus de suscetibilidade}

Para a geração do cenário, foram definidos os graus de suscetibilidade, de cada classe, dos mapas que compõe os parâmetros selecionados supracitados na modelagem realizada. Inicialmente, foram definidas três classes de suscetibilidade (baixa, média e alta), conforme os trabalhos de Pfaltzgraff (2007), de Torres (2014) e de Menezes Júnior (2015). 
Os graus de suscetibilidade e a definição dos pesos atribuídos foram definidos por meio de trabalhos prévios, que utilizaram o modelo AHP em áreas próximas, tais como Torres (2014) e Menezes Júnior (2015), além de trabalhos de campo para validação. Geologicamente, das quatro unidades presentes na área (formação barreiras, depósitos fluviais, depósitos litorâneos e depósito de manguezais), a formação barreiras foi considerada a mais suscetível e com maior peso (Tabela 1), em função da presença de sedimentos pouco ou mal consolidados. Para os depósitos litorâneos e fluviais, foi atribuído um grau médio de suscetibilidade, devido aos depósitos arenosos e areno-argilosos e fluviais (Tabela 1) Os depósitos de manguezais receberam os menores pesos, uma vez que se situam em áreas topograficamente mais planas (Tabela 1).

Tabela 1: Classificação do grau de suscetibilidade a escorregamentos: Geologia

\begin{tabular}{lcl}
\hline \multicolumn{1}{c}{ Unidades Geológicas } & $\begin{array}{c}\text { Grau de } \\
\text { Suscetibilidade }\end{array}$ & \multicolumn{1}{c}{ Características Gerais } \\
\hline $\begin{array}{l}\text { Depósitos de Manguezais } \\
\text { Depósitos Litorâneos }\end{array}$ & 1 & Sedimentos compostos por areia, silte e materiais orgânicos. \\
$\begin{array}{l}\text { Depósitos Fluviais } \\
\text { Formação Barreiras }\end{array}$ & 2 & $\begin{array}{l}\text { Depósitos arenosos e areno-argilosos e fluviais. } \\
\text { Sedimentos pouco ou mal consolidados, depósitos de areias } \\
\text { grossas, intercaladas por estratos de areia fina e/ou argila. }\end{array}$ \\
\hline
\end{tabular}

Fonte: Autoria própria (2020)

Geomorfologicamente, as encostas são a classe mais suscetível (Tabela 2), por apresentarem modelados de denudação com forte influência da declividade. Para os tabuleiros dissecados e os tabuleiros convexos foram adotados valores intermediários, à medida que representam modelados de denudação (Tabela 2). A planície flúviomarinha e a planície fluvial receberam os menores pesos (áreas planas) (Tabela 2).

Tabela 2: Classificação do grau de suscetibilidade a escorregamentos: Geomorfologia

\begin{tabular}{ccl}
\hline Unidades Geomorfológicas & $\begin{array}{c}\text { Grau de } \\
\text { Suscetibilidade }\end{array}$ & \multicolumn{1}{c}{ Características Gerais } \\
\hline $\begin{array}{c}\text { Planície Fluviomarinha } \\
\text { Planície Fluvial }\end{array}$ & 1 & Modelados de acumulação. \\
$\begin{array}{c}\text { Tabuleiros Dissecados } \\
\text { Tabuleiros Convexos }\end{array}$ & 2 & Modelados de denudação. \\
Encostas & 3 & Modelados de denudação, forte influência da declividade. \\
\hline
\end{tabular}

Fonte: Autoria própria (2020)

Com relação aos solos, os argissolos foram classificados como a classe mais suscetível (Tabela 3), por apresentarem teor substancial de argila de alta atividade, ou seja, maior capacidade de retenção de água, facilmente expansíveis, limitando a sua drenagem natural. Os latossolos classificaram-se com suscetibilidade média uma vez que apresentam descontinuidades entre seus horizontes (Tabela 3). Por fim, os neossolos quartzarênicos, os neossolos flúvicos e os solos indiscriminados de mangue receberam os menores pesos (Tabela 3), por caracterizarem-se como arenosos e com permeabilidades muito altas, distribuídos nas planícies marinhas e nas restingas, nos coqueirais e em extensões urbanas.

Tabela 3: Classificação do grau de suscetibilidade a escorregamentos: Solos

\begin{tabular}{|c|c|c|}
\hline Classes de solos & $\begin{array}{c}\text { Grau de } \\
\text { Suscetibilidade }\end{array}$ & Características Gerais \\
\hline Neossolos Quartzarênicos & & Solos arenosos com permeabilidade muito alta, distribuídos \\
\hline Neossolos Flúvicos & & $\begin{array}{l}\text { nas planícies marinhas e restingas, local dos coqueirais e } \\
\text { extensões urbanas. }\end{array}$ \\
\hline $\begin{array}{l}\text { Solos Indiscriminados de } \\
\text { Mangue } \\
\text { Gleissolos Háplicos }\end{array}$ & 1 & $\begin{array}{l}\text { Solos halomórficos pouco desenvolvidos. Constituído por } \\
\text { sedimentos recentes, de natureza mineral em mistura com } \\
\text { matéria orgânica. }\end{array}$ \\
\hline Latossolos & 2 & $\begin{array}{l}\text { Solos homogêneos e profundos, apresentam pouca } \\
\text { diferenciação entre os horizontes. }\end{array}$ \\
\hline Argissolos & 3 & $\begin{array}{l}\text { Solos minerais, apresentam diferenciação entre os horizontes } \\
\text { são bastantes suscetíveis a escorregamentos. }\end{array}$ \\
\hline
\end{tabular}


Quanto às formas da encosta, em seus perfis vertical e horizontal atribuiu-se a maior suscetibilidade às encostas côncava/convergente, retilínea/convergente e côncava/planar, por favorecerem o escoamento superficial concentrado (Tabela 4). De suscetibilidade média, destacam-se as encostas convexa/convergente, côncava/divergente e convexa/divergente, devido relativa dispersão do fluxo hídrico nas encostas (Tabela 4). As encostas convexa/planar, retilínea/planar e retilínea/divergente receberam menores pesos devido escoamento superficial disperso (Tabela 4).

Tabela 4: Classificação do grau de suscetibilidade a escorregamentos: Formas da encosta

\begin{tabular}{|c|c|c|}
\hline $\begin{array}{c}\text { Curvaturas Horizontais } \mathbf{X} \\
\text { Verticais do terreno }\end{array}$ & Grau de Suscetibilidade & Características \\
\hline Convexa/Planar & \multirow{3}{*}{1} & \multirow{3}{*}{$\begin{array}{l}\text { Formas que favorecem a dispersão do } \\
\text { escoamento superficial sem afetar muito às } \\
\text { encostas. }\end{array}$} \\
\hline Retilínea/Planar & & \\
\hline Retilínea/Divergente & & \\
\hline $\begin{array}{l}\text { Convexa/Convergente } \\
\text { Côncava/Divergente } \\
\text { Convexa/Divergente }\end{array}$ & 2 & $\begin{array}{l}\text { Apresentam tendência de dispersão do } \\
\text { fluxo hídrico ao longo da encosta. }\end{array}$ \\
\hline Côncava/Convergente & \multirow{3}{*}{3} & \multirow{3}{*}{$\begin{array}{l}\text { Formas que possibilitam concentração dos } \\
\text { fluxos hídricos aumentando a } \\
\text { suscetibilidade a escorregamentos. }\end{array}$} \\
\hline Retilínea/Convergente & & \\
\hline Côncava/Planar & & \\
\hline
\end{tabular}

Fonte: Autoria própria (2020)

Para a declividade atribuiu-se maior suscetibilidade ao intervalo $16,8^{\circ}>$ (Tabela 5) devido relevo fortemente íngreme com maior instabilização dos materiais (saturação hídrica e inclinação da vertente). A classe $9,7^{\circ}$ e $16,7^{\circ}$ recebeu valores médios (índice moderado de escorregamentos) e a classe $0^{\circ}$ e $9,6^{\circ}$, os menores valores, devido planitude do relevo e menor probabilidade de rupturas (Tabela 5).

Tabela 5: Classificação do grau de suscetibilidade a escorregamentos: Declividade

\begin{tabular}{clc}
\hline Intervalos de Declividade & \multicolumn{1}{c}{ Feições Morfológicas } & Grau de suscetibilidade \\
\hline $0^{\circ}-9,6^{\circ}$ & $\begin{array}{l}\text { Relevo plano a suave ondulado. Baixo índice } \\
\text { de escorregamento. }\end{array}$ & 1 \\
$9,7^{\circ}-16,7^{\circ}$ & $\begin{array}{l}\text { Relevo ondulado. Índice moderado de } \\
\text { escorregamento. }\end{array}$ & $\begin{array}{l}\text { Padrão de relevo montanhoso o qual } \\
\text { apresenta elevada suscetibilidade a } \\
\text { escorregamentos. }\end{array}$ \\
$16,8^{\circ}>$ & & 3 \\
\hline
\end{tabular}

Fonte: Autoria própria (2020)

\subsection{Estruturação do AHP e cenário de suscetibilidade}

A carta de suscetibilidade foi realizada, inicialmente, por meio da estruturação hierárquica do modelo AHP considerando os critérios/mapeamentos supracitados: Critério 1 (C1) - geomorfologia, C2-geologia, C3-formas da encosta, C4-declividade e C5-solos. Os mapas (Figura 3) foram convertidos em raster em ambiente SIG, visando-se realizar a álgebra de mapas. 


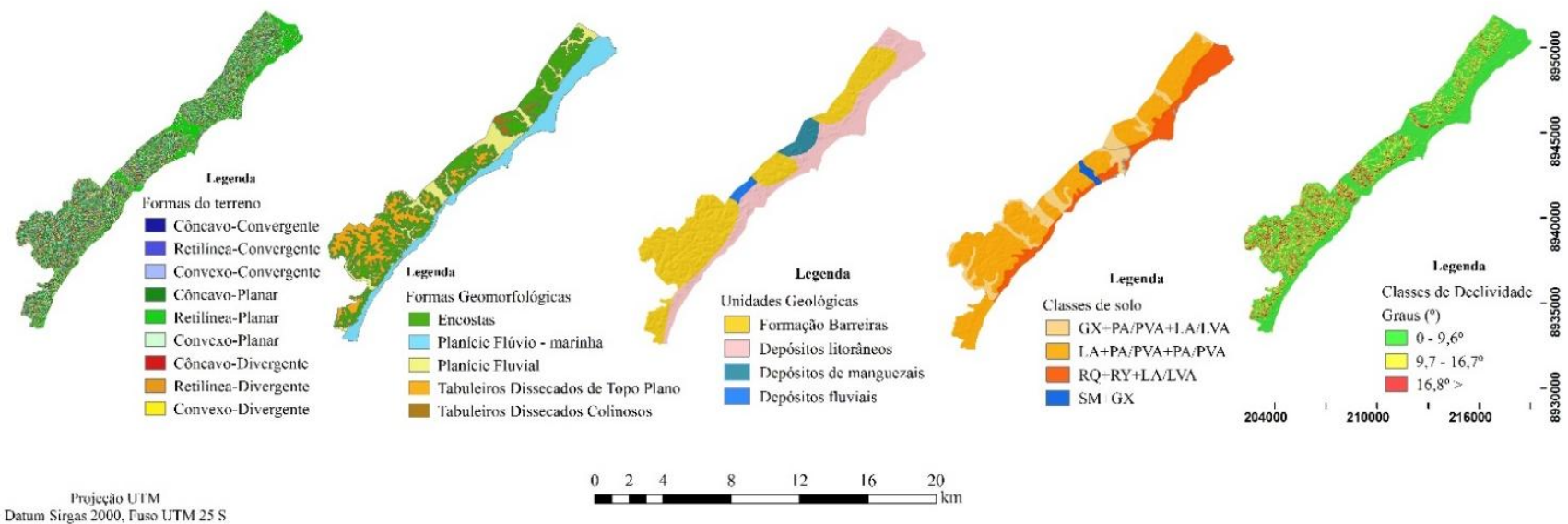

Figura 3: Critérios utilizados na elaboração do mapa de suscetibilidade. Fonte: Autoria própria (2020)

Em seguida, foi realizada uma comparação pareada dos elementos em cada nível do sistema, constituindo-se em um julgamento comparativo por meio da atribuição de pesos, procurando-se determinar a importância relativa de cada elemento de um nível hierárquico com relação a cada critério da árvore hierárquica. no nível imediatamente superior. Os pesos foram definidos tomando por referência a Escala Fundamental da AHP (SAATY,1991; 2008). Essa escala (Tabela 6), apresenta valores de intensidade de importância entre 1 a 9.

Tabela 6: Exemplo da Escala Fundamental da AHP

\begin{tabular}{|c|c|c|}
\hline $\begin{array}{l}\text { Intensidade de } \\
\text { Importância }\end{array}$ & Definição & Explicação \\
\hline 1 & Igual Importância & $\begin{array}{l}\text { Duas atividades contribuem igualmente com o } \\
\text { objetivo }\end{array}$ \\
\hline 3 & $\begin{array}{l}\text { Importância moderada de um } \\
\text { sobre o outro }\end{array}$ & $\begin{array}{l}\text { Experiência e julgamento favorecem fortemente } \\
\text { uma atividade sobre a outra }\end{array}$ \\
\hline 5 & Essencial ou forte importância & $\begin{array}{l}\text { Experiência e julgamento favorecem fortemente } \\
\text { uma atividade sobre a outra }\end{array}$ \\
\hline 7 & Importância muito forte & $\begin{array}{l}\text { Uma atividade é fortemente favorecida e seu } \\
\text { domínio é demonstrado na prática }\end{array}$ \\
\hline 9 & Extremamente importante & A evidência favorece uma atividade sobre a outra \\
\hline $2,4,6,8$ & $\begin{array}{l}\text { Valores intermediário entre dois } \\
\text { julgamentos adjacentes }\end{array}$ & Quando o compromisso é necessário \\
\hline
\end{tabular}

Fonte: Modificado de Saaty $(1991 ; 2008)$

Por meio de critérios pré-selecionados (geologia, geomorfologia, solos, formas da encosta e declividade) foi utilizada uma matriz quadrada, com análise pareada, culminando em um peso para cada critério/parâmetro conforme exemplo na Tabela 7.

Tabela 7: Matriz quadrada de correlação pareada do cenário de suscetibilidade

\begin{tabular}{c|ccccc}
\hline Critérios & Geomorfológico & Geológico & Solos & Declividade & $\begin{array}{c}\text { Forma do } \\
\text { terreno }\end{array}$ \\
\hline Geomorfológico & 1 & 1,00 & 1,00 & 1,00 & 1,00 \\
Geológico & 1 & 1 & 1 & 0,25 & 1,00 \\
Solos & 1 & 1 & 1 & 0,25 & 0,50 \\
Declividade & 1 & 4 & 4 & 1 & 1 \\
Forma do terreno & 1 & 1 & 2 & 1 & 1 \\
\hline
\end{tabular}

Fonte: Autoria própria (2020) 
Após a comparação pareada por meio da matriz quadrada, foi realizada a normalização dos valores, cujo valor de importância determinado para cada par é dividido pelo somatório dos valores de cada coluna. Desta forma, para a aquisição do valor do peso (wi) de cada critério, foi realizada a divisão do somatório de cada linha $(\mathbf{\Sigma} \mathbf{L})$ pelo número de critérios analisados, conforme a Tabela 8.

Tabela 8: Matriz quadrada de correlação pareada do cenário de suscetibilidade

\begin{tabular}{c|cccccc}
\hline Critérios & Geomorfológico & Geológico & Solos & Declividade & $\begin{array}{c}\text { Forma do } \\
\text { terreno }\end{array}$ & $\begin{array}{c}\text { Wi } \\
\text { (peso) }\end{array}$ \\
\hline $\begin{array}{c}\text { Geomorfológico } \\
\text { Geológico }\end{array}$ & 0,20 & 0,13 & 0,11 & 0,29 & 0,29 & 0,19 \\
$\begin{array}{c}\text { Solos } \\
\text { Declividade } \\
\text { Forma do } \\
\text { terreno }\end{array}$ & 0,20 & 0,13 & 0,11 & 0,07 & 0,07 & 0,15 \\
\hline
\end{tabular}

Fonte: Autoria própria (2020)

Após a comparação pareada, busca-se o valor de consistência, visando confirmar a validade do resultado obtido, por meio do cálculo da Razão de Consistência (RC). Este permite avaliar a inconsistência em função da ordem da matriz de julgamentos (Equação 1).

$$
\mathrm{RC}=\mathrm{IC} / \mathrm{IR}
$$

Eq. 1

Onde $: \mathbf{R C}=$ Razão de Consistência; $\mathbf{I C}=$ Índice de Consistência) e IR = (Índice Randômico)

O Cálculo do Índice de Consistência (IC) avalia o grau de inconsistência da matriz de julgamentos paritários (Equação 2).

$$
\mathrm{IC}=(\lambda \max -\mathrm{n}) /(\mathrm{n}-1), \text { onde } \mathrm{o} \lambda \max =1 / \mathrm{n} \mathrm{Sni}=1[\mathrm{Aw}] / \mathrm{wi}
$$

Onde $: \mathbf{n}=$ número de ordem da matriz; $\lambda \mathbf{m a x}=$ autovetor; $\mathbf{W i}=$ pesos calculados e $\mathbf{A} \mathbf{w}=$ Produto entre $\mathbf{W i}$ com a matriz de correlação pareada

A tolerabilidade da inconsistência desta matriz é denominada Índice Randômico, fornecido por uma tabela de valores (Tabela 9) e é função da dimensão da matriz de comparação. O IR é obtido para uma matriz randômica recíproca, com elementos não-negativos. Inúmeros tamanhos de matriz $\mathrm{N}$ foram aproximados por Saaty (1991), tendo como base simulações em laboratório.

Tabela 9: Valores de IR em função da ordem da matriz quadrada

\begin{tabular}{cccccccccccccccc}
\hline $\mathbf{N}$ & $\mathbf{1}$ & $\mathbf{2}$ & $\mathbf{3}$ & $\mathbf{4}$ & $\mathbf{5}$ & $\mathbf{6}$ & $\mathbf{7}$ & $\mathbf{8}$ & $\mathbf{9}$ & $\mathbf{1 0}$ & $\mathbf{1 1}$ & $\mathbf{1 2}$ & $\mathbf{1 3}$ & $\mathbf{1 4}$ & $\mathbf{1 5}$ \\
$\mathbf{I R}$ & 0 & 0 & 0,53 & 0,89 & 1,11 & 1,25 & 1,35 & 1,40 & 1,45 & 1,49 & 1,52 & 1,54 & 1,56 & 1,58 & 1,59 \\
\hline
\end{tabular}

Fonte: Saaty (2008)

A partir do IC e do IR, adquire-se o valor de RC (Razão de Consistência). A RC mensura a coerência e a consistência das relações de importância consideradas na análise. Assim, caso seja superior a 0,10 , o julgamento dos condicionantes deve ser refeito, devido incoerências. Quanto mais próxima de "0" for a razão de consistência, mais coerente será o modelo. Para valores de $\mathrm{RC}>0,10$ pede-se uma revisão na matriz de comparações (CARVALHO, RIEDEL, 2005; SAATY 1991, 2008; TORRES, 2014). A razão de consistência obtida para o cenário da suscetibilidade produzido neste artigo foi de 0,07 , portanto dentro dos limites recomendados pela literatura.

\subsection{Validação do cenário de suscetibilidade}

Para a validação do cenário de suscetibilidade realizou-se, primeiramente, um mapeamento das ocorrências de cicatrizes de escorregamentos em 2017 (Figura 1). O mapa de escorregamentos objetivou analisar a distribuição das cicatrizes, assim como sua tipologia, tamanho, forma e estado de atividade. Para a delimitação das cicatrizes foram consideradas somente a área de ruptura, desconsiderando suas áreas de 
arraste e de depósito, conforme proposto por Martins; Oka-Fiori; Vieira (2015), observando-se as diferenças de textura de solo e aspectos alongados.

A delimitação das cicatrizes foi realizada na forma de vetores do tipo polígono $\mathrm{em}$ ambiente SIG, a partir da interpretação de imagens de satélite disponibilizadas pelo software Google Earth Pro. Posteriormente, foi realizado trabalho de campo para validar as cicatrizes mapeadas.

Por meio da sobreposição do inventário de cicatrizes e do cenário de suscetibilidade, foi utilizado o seguinte índice para validação com base no método proposto por Gao (1993): Concentração de Cicatrizes de Escorregamentos (CCE): razão entre o número de células, de cada classe, afetadas pelas cicatrizes e o total de células afetadas na área.

\section{Resultados e discussão}

\subsection{Cenário de suscetibilidade}

O mapa de suscetibilidade a escorregamentos (Figura 4) apresentou uma Frequência de Distribuição (FD) de 26\% para as classes de baixa suscetibilidade; 64\% média e, somente, $10 \%$ de alta suscetibilidade. (Figura 5). Todas as classes de suscetibilidade encontram-se em maior ou menor densidade distribuídas por toda a extensão da área estudada.

Por meio de correlações realizadas em ambiente SIG, assim como pelas observações nos trabalhos de campo, constatou-se que as áreas de suscetibilidade baixa possuem declividades suavizadas $\left(0^{\circ} \mathrm{e} 9,6^{\circ}\right)$, não possibilitando o fluxo rápido de massas de solo ou rocha pelo efeito da gravidade, como constatado nos trabalhos de Guidicini e Nieble (1984); Listo e Vieira (2010), entre outros. Com formas de terreno predominantemente retilínea/planar, essas reduzem o impacto da água com dispersão do fluxo, localizadas nas planícies fluvial e costeiras expressivas neste grau de suscetibilidade (Figura 4a), assim como visto em Valeriano e Carvalho Júnior (2003).

Quanto ao padrão geológico, observou-se que o grau de suscetibilidade baixo corresponde as classes dos depósitos litorâneos, fluviais e de manguezais. Pedologicamente, correspondem ao grau de baixa suscetibilidade, os Gleissolos Háplicos, os Neossolos Quartzarênicos e os Neossolos Flúvicos.

Nas áreas de média suscetibilidade (Figura 4b), há formas convexas com declividades entre $9,6^{\circ}$ e $16,7^{\circ}$. Geologicamente, correspondem a formação barreiras, com características físicas que contribuem para elevar o grau de suscetibilidade da área. Os tabuleiros (topo planar e convexo), assim como, os latossolos e argissolos derivados desta formação, também contribuem significativamente para o grau de suscetibilidade médio.

As áreas de suscetibilidade alta possuem declividades bastante íngremes $\left(16,8^{\circ}>\right)$ (Figura 4c), favorecendo o fluxo rápido de massas de solo ou rocha pelo efeito da gravidade, em concordância com o observado nos trabalhos de Guidicini e Nieble (1984) e Listo e Vieira (2010). Predominam formas côncavas, que aceleram o impacto da água com concentração do fluxo, como demonstrado por Valeriano e Carvalho Júnior (2003).

As encostas são os principais modelados responsáveis pela elevação do grau de suscetibilidade. Quanto ao padrão geológico, observou-se que o grau de suscetibilidade alto possui influência significativa da formação barreiras. O fator solo apresenta os argissolos e os latossolos como condicionantes significativos para elevar o grau de suscetibilidade, corroborando com o estudo sobre suscetibilidade a escorregamentos realizado no município de Maceió por Rodrigues, Calheiros e Melo (2007).

Os resultados expostos no mapa de suscetibilidade permitem afirmar que as áreas de baixa suscetibilidade estão aptas a ocupação, sem riscos eminentes quanto a processos de escorregamentos. As áreas que correspondem à suscetibilidade média podem ser ocupadas desde que se adequem às normas técnicas e ambientais. Nas áreas com suscetibilidade alta não é recomendada a ocupação devido a associação de fatores que potencializam a ocorrência de escorregamentos, a menos que sejam realizadas obras de engenharia, que possibilitem a ocupação. 


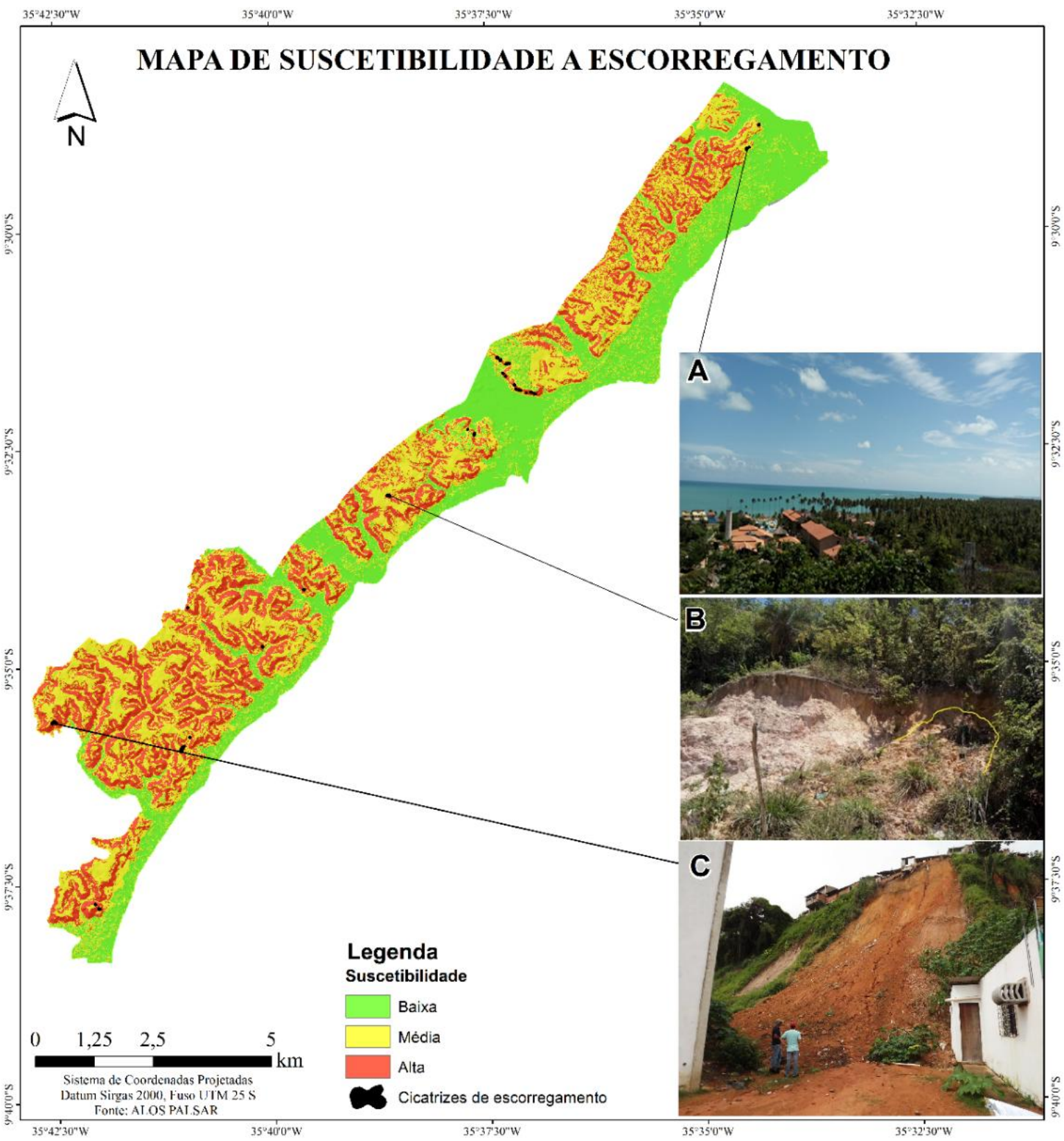

Figura 4. Mapa de suscetibilidade a escorregamentos gerado pelo modelo AHP. A) Planície Costeira de Maceió (área de baixa suscetibilidade). B) Cicatriz de escorregamento em uma área de suscetibilidade média. C) Cicatriz de Escorregamento em uma área de suscetibilidade alta. Fonte: Autoria própria (2018).

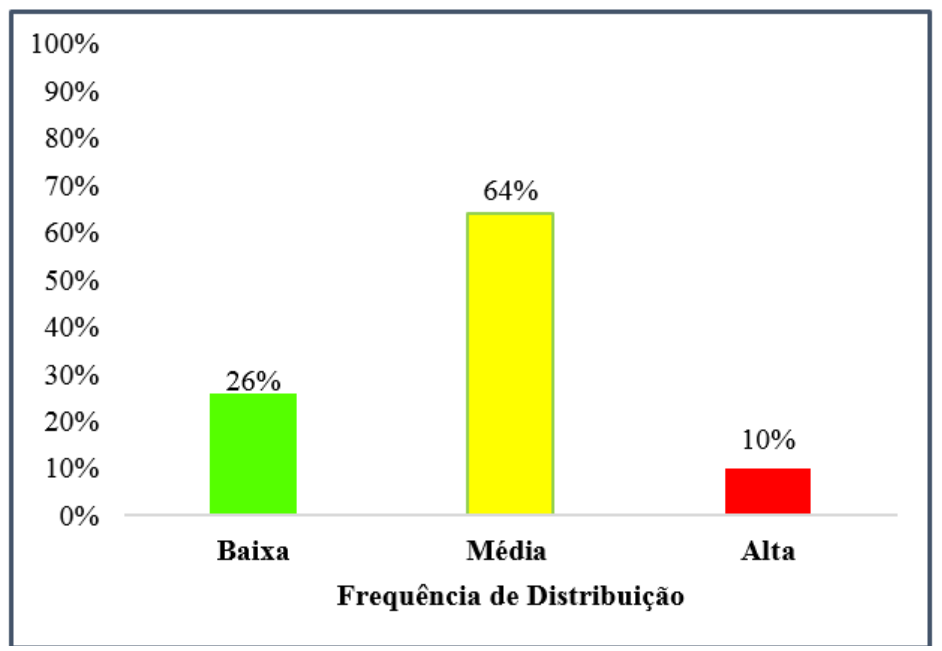

Figura 5. Frequência de Distribuição do mapa de suscetibilidade. Fonte: Autoria própria (2020) 


\subsection{Análise dos resultados e validação do cenário de suscetibilidade}

O fator condicionante com maior importância para a deflagração de escorregamentos foi a declividade, com um peso de 0,33 (33\% de influência sobre o valor final da suscetibilidade). As encostas mais declivosas, embora não sejam o único fator condicionante, favorecem de forma significativa a deflagração dos processos, principalmente, pelo aumento da velocidade do escoamento superficial e do poder erosivo na movimentação de materiais superficiais, elevando a suscetibilidade, assim como já constatado nos estudos de Selby 1993; Listo (2011) e CPRM/IPT (2014).

O segundo critério condicionante com maior importância foi a forma da encosta, com um peso de 0,21 ( $21 \%$ de influência sobre o valor final de suscetibilidade). O peso adotado está de acordo com outros estudos, cuja forma do terreno assume importância considerável na determinação da suscetibilidade, relação vista em Valeriano e Carvalho Júnior, (2003); Cardozo e Herrmann (2011) e Torres (2014). De acordo com Selby (1993), as formas do terreno são condicionantes significativos para a deflagração de escorregamentos, sendo as formas côncava/convergente; retilínea/convergente; côncava/planar, as que possuem maior capacidade de aumentar o fluxo hídrico. Quando correlacionado com a declividade, verifica-se uma alta preponderância sobre as encostas abruptas, ou seja, atua como condicionante importante na suscetibilidade a processos de escorregamentos.

O parâmetro geomorfológico recebeu um peso 0,19. Esse valor é condizente com pesquisas realizadas por Cardozo e Herrmann (2011). Foram considerados com base em Crepani et al. (2001), considerou-se que a morfologia do relevo é um fator importante para determinar a suscetibilidade de uma área quanto a ocorrência de processos superficiais da paisagem, como por exemplo, escorregamentos, dessa forma, julgouse as influências da dissecação do relevo, a amplitude altimétrica assim como a declividade.

Geologicamente, obteve-se um peso de 0,15 . Os escorregamentos na área estão fortemente controlados pelas unidades geológicas (principalmente a Formação Barreiras). Estas possuem diferentes mineralogias, graus de intemperismo, e, portanto, suscetibilidades distintas conforme observado em Brito (2014); Torres, (2014).

O fator solo resultou no peso 0,12 . Foi considerado o grau de maturidade dos solos da área, sua relação morfogênese/pedogênese e suas condições de estabilidade, conforme visto em: Crepani et al. (2001); Rodrigues, Calheiros, Melo (2007); Torres (2014).

Com base nas análises supracitadas, a razão de consistência obtida para o cenário da suscetibilidade foi de 0,07. Tal valor indica que os julgamentos apresentaram uma consistência aceitável conforme Saaty $(1991 ; 2008)$. Desta forma, os pesos atribuídos foram coerentes na modelagem da suscetibilidade a escorregamentos.

Um outro elemento que atesta a viabilidade do mapeamento de suscetibilidade realizado nesta pesquisa, foram os resultados exportados pelo inventário de escorregamentos, mapeou-se 29 cicatrizes de escorregamentos (Figura 1). O mapeamento permitiu verificar que as cicatrizes estão distribuídas ao longo de toda área estudada.

A partir da sobreposição das cicatrizes de escorregamentos no mapa de suscetibilidade (Figura 4), constatou-se que das 29 cicatrizes mapeadas, obteve-se uma Concentração de Cicatrizes de Escorregamentos - CCE equivalente a $69 \%$ na classe de suscetibilidade alta; $30 \%$ nas classes de suscetibilidade média e, apenas, $1 \%$ na classe de suscetibilidade baixa (Figura 6) indicando sucesso na previsão realizada. Nesse sentido, as áreas previstas pelo modelo como mais suscetíveis (e mais instáveis) localizaram-se em sua maioria sobre as cicatrizes de escorregamentos.

A pesquisa de Torres (2014) corrobora com o resultado encontrado nesta pesquisa, na medida em que a autora por meio da aplicação do método AHP em um estudo sobre suscetibilidade a escorregamentos no município de Ipojuca no Estado de Pernambuco, com condições geoambientais e fatores condicionantes (geologia, geomorfologia, solos, declividade e formas da encosta) semelhantes à pesquisa realizada em Maceió, Alagoas, conseguiu resultados expressivos para o modelo adquirido. De 103 cicatrizes de escorregamentos identificadas, $53 \%$ dos escorregamentos estavam concentrados nas classes de suscetibilidade alta; $44 \%$ na classe de suscetibilidade média e $4 \%$ na classe de suscetibilidade baixa.

Brito (2014) também aplicou o método AHP para analisar a suscetibilidade a escorregamentos no município de Porto Alegre (RS), considerando quatro variáveis: declividade, geologia, distância de lineamentos e acúmulo de fluxo para obtenção da suscetibilidade. O modelo exportou resultados significativos diante da validação. Das 107 cicatrizes identificadas, 95,2\% delas estavam concentradas nas classes de suscetibilidade alta e muito alta; $2,8 \%$ na classe de suscetibilidade média e 1,8\% na classe de suscetibilidade baixa, resultados que comprovaram a validade do modelo adquirido. 


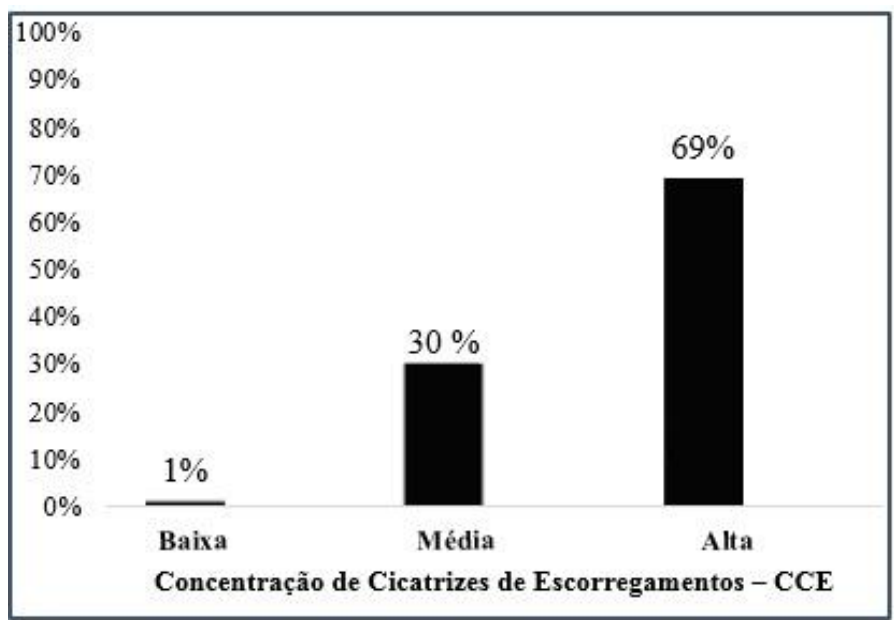

Figura 6. Concentração de Cicatrizes de Escorregamentos (CCE) no mapa de suscetibilidade. Fonte: Autoria própria (2020)

Destarte, os resultados expressos pela validação dos mapas de suscetibilidade da presente pesquisa, as sim como nos dois exemplos citados anteriormente, indicam conforme o esperado, que a maior parte dos escorregamentos estão inseridos na classe de suscetibilidade alta. Afirma-se que os resultados do modelo aplicado se assemelham com a realidade, apresentando taxa de acurácia satisfatória para ser validado e aplicado.

\section{Considerações finais}

O modelo AHP permitiu a elaboração um mapeamento com acurácia mostrando o quadro ambiental da área estuda, indicando áreas próprias e impróprias para o uso e ocupação, cujos resultados apresentados atenderam ao principal objetivo deste artigo, avaliar a suscetibilidade a escorregamentos no litoral norte de Maceió.

A modelagem final apresentou grau de confiança aceitável com RC igual a 0,07. O índice de FD mostrou que $26 \%$ da área apresentou classes de baixa suscetibilidade; $64 \%$ média e, $10 \%$ de alta suscetibilidade. Para termos de validação, na CCE obteve-se apenas $1 \%$ das cicatrizes de escorregamentos em áreas de baixa suscetibilidade, demonstrando que os outros $99 \%$ das cicatrizes estavam dispostas nas áreas de suscetibilidade média (30\%) e/ou alta (69\%), o que torna o mapeamento válido.

Dentre os critérios utilizados no mapeamento constatou-se que as encostas são os modelados mais suscetíveis a escorregamentos, principalmente, quando correlacionadas com a forte influência da declividade e dos padrões côncavos do terreno.

Para fins de planejamento territorial recomenda-se que as áreas que apresentam suscetibilidade alta sejam preservadas, considerando-se o seu papel modelador da paisagem e mantenedor do equilíbrio ecológico. Tais áreas devem ser enquadradas como Zonas de Interesse Ambiental e Paisagístico (ZIAPs) de acordo com a Lei municipal 5.593/07 (Código de Urbanismo e Edificações de Maceió) ou seja, Áreas de Preservação Permanente (APPs), conforme recomenda o Código Florestal Brasileiro (Maceió, 2007 b). Para as áreas que já se encontram consolidadas/ocupadas é importante o monitoramento por parte dos órgãos competentes do município de Maceió.

As ferramentas de geoprocessamento juntamente com o método AHP, contribuíram significativamente para o diagnóstico de suscetibilidade. Destaca-se que a incorporação do método AHP nos mapeamentos de suscetibilidade a escorregamentos é uma das principais contribuições desta pesquisa no sentido de diminuir a limitação no tocante a subjetividade destes mapeamentos comumente adotados via métodos heurísticos. Porém, é sabido que uso do AHP ainda não é consenso entre os pesquisadores, havendo algumas críticas relativas à forma de estruturação dos problemas, embora menos subjetivo. Futuramente pretende-se realizar testes com outros métodos para avaliação e comparação de resultados.

\section{Agradecimentos}

Os autores agradecem ao Conselho Nacional de Desenvolvimento Científico e Tecnológico (CNPq) pelo financiamento desta pesquisa e a Coordenadoria Municipal de Defesa Civil (COMDEC) de Maceió pelo 
acompanhamento nos trabalhos de campo. Agradecem também aos pareceristas anônimos pelas alterações, sugestões e revisões.

\section{Referências}

AUGUSTO FILHO, O. Caracterização geológico-geotécnica voltada à estabilização de encostas: uma proposta metodológica. In: Conferência Brasileira sobre Estabilidade de Encostas, 1992, Rio de Janeiro. Anais... Rio de Janeiro: ABMS/ABGE/PUCRJ, 1992. p.721-733.

BRASIL. Lei Federal n. 6.766, de 19 de dezembro de 1979. Dispõe sobre o parcelamento do solo urbano e dá outras providências. Diário Oficial da União, Brasília, 29 de dezembro de 1979. Disponível em: <http://www.planalto.gov.br/> Acesso em: 10 jan. 2017.

BRASIL. Mapeamento de Riscos em Encostas e Margem de Rios. Celso Santos Carvalho, Eduardo Soares de Macedo e Agostinho Tadashi Ogura, (orgs). - Brasília: Ministério das Cidades; Instituto de Pesquisas Tecnológicas - IPT, 2007. 175 p.

BRITO, M. M. Geoprocessamento aplicado ao mapeamento da suscetibilidade a escorregamentos no município de Porto Alegre, RS. 2014. 167 f. Dissertação (Mestrado em Engenharia) - Programa de PósGraduação em Engenharia Civil, UFRGS, 2014.

CAMARINHA, P. I. M.; CANAVESI, V.; ALVALÁ, R. C. S. Shallow landslide prediction and analysis with risk assessment using a spatial model in a coastal region in the state of São Paulo, Brazil. Natural Hazards and Earth System Sciences, v. 14, 2449-2468, 2014.

CARDOZO, F. S.; HERRMANN, M. L. P. Uso da técnica AHP no mapeamento de áreas suscetíveis a escorregamentos. In: Simpósio Brasileiro de Sensoriamento Remoto, 15; 2011, Curitiba. Anais... Curitiba: Instituto Nacional de Pesquisas Espaciais, 2011. p. 4134-4141.

CARVALHO, C. M.; RIEDEL, P. S. Técnicas de Geoprocessamento aplicadas ao estudo da suscetibilidade a escorregamentos. In: XII Simpósio Brasileiro de Sensoriamento Remoto, 9; 2005, Goiânia. Anais... Goiânia: INPE, 2005. p. 2901 - 2908.

COSTA, J. de A.; RAMOS, V. A. Espaço urbano de Maceió: ambiente físico e organização sócio econômica. In: ARAUJO, L.M. Geografia espaço, tempo e planejamento. Maceió: Edufal, 2004. pp. 191205.

CPRM, IPT. Cartas de suscetibilidade a movimentos gravitacionais de massa e inundações: 1:25.000. Coordenação Omar Yazbek Bitar. São Paulo: IPT - Instituto de Pesquisas Tecnológicas do Estado de São Paulo. Brasília: CPRM - Serviço Geológico do Brasil, 2014.

CREPANI, E. et al. Sensoriamento Remoto e Geoprocessamento Aplicados ao Zoneamento Ecológico Econômico e ao Ordenamento Territorial. INPE, São José dos Campos, 2001.

FELL, R. et al. Guidelines for landslide susceptibility, hazard and risk zoning for land-use planning. Engineering Geology. v. 102, 83-111, 2008.

GAO, J. Indentification of Topographic Settings Conductive to Landsliding from Nelson County, Virginia, U.S.A. Earth Surface Processes and Landforms, 1993. 79-591p.

GUERRA A J T. et al. Slope Processes, Mass Movement and Soil Erosion: A Review. Pedosphere. v. 27, 27-41, 2017.

GUIDICINI, G.; NIEBLE, C. M. Estabilidade de taludes naturais e de Escavação. 2. ed. São Paulo: Edgard Blücher; 1984.

Instituto Brasileiro de Geografia e Estatística - IBGE. População estimada, 2018.

Disponível em: < https://cidades.ibge.gov.br/brasil/al/maceio/ >. Acesso em: 02 maio de 2019. 
Instituto Brasileiro de Geografia e Estatística - IBGE. Coordenação de Recursos Naturais e Estudos Ambientais. Manual técnico de geomorfologia - 2. ed. - Rio de Janeiro: IBGE, 2009.182 p.

LISTO, F. L. R.; VIEIRA, B. C. Análise de Condicionantes Topográficos como subsídio para avaliação de áreas de risco a escorregamentos rasos. Recife, Revista de Geografia, vol. especial, n. 3, 193-207, 2010.

LISTO, F. L. R. Análise da suscetibilidade e do grau de risco a escorregamentos rasos na bacia do Alto Aricanduva, RMSP (SP). 2011. 151 f. Dissertação (Mestrado em Geografia) - Faculdade de Filosofia, Letras e Ciências Humanas, Universidade de São Paulo, São Paulo, 2011.

MACEIÓ. Plano Municipal de Redução de Risco. Maceió: Prefeitura Municipal, 2007 a.

MACEIÓ. Lei municipal n. 5.593, de fevereiro de 2007. Maceió: Prefeitura Municipal, 2007 b.

MARTINS, T.D.; OKA-FIORI, C.; VIEIRA, B. C. Mapeamento de cicatrizes de escorregamentos utilizando imagem multiespectral. Revista do Departamento de Geografia. v. 30, 96-109, 2015.

MENEZES JÚNIOR, E. M. Análise geomorfológica da suscetibilidade a deslizamentos na folha Paulista (1:25.000) 2015. 156 f. Dissertação (Mestrado em Geografia) - UFPE, Recife, 2015.

MOLION, L.C.B.; BERNARDO, S.O. Uma revisão da dinâmica das chuvas no Nordeste brasileiro. Revista Brasileira Meteorologia. v. 17, 1-10, 2002.

PFALTZGRAFF, P. A. dos S. Mapa de suscetibilidade a deslizamentos da região metropolitana de Recife. 2007. Tese (Doutorado). Programa de Pós-Graduação em Geociências, Universidade Federal de Pernambuco, Recife, 2007.

REIS, S.; et al. Remote sensing and GIS-based landslide susceptibility mapping using frequency ratio and analytical hierarchy methods in Rize province (NE Turkey). Environmental Earth Sciences. v. 66, n. 7 , 2063-2073, 2012.

RODRIGUeS, B. T.; CALHEIROS, S. Q. C.; DE MELO, N. A. Potencial de movimento de massa no município de Maceió-Alagoas. Geo UERJ. v. 1, n. 24, 207-227, 2007.

SAATY, T. L. Método de Análise Hierárquica. São Paulo: Mcgraw-hill, 1991.

SAATY, T. L. Relative measurement and Its generalization in decision making why Pairwise comparisons are Central in mathematics for the measurement of intangible factors the Analytic Hierarchy Process. Rev. R. Acad. Cien. Serie A. Mat. - RACSM. v.102, n. 2, 251-318, 2008.

SHAHABI, H. et al. Landslide susceptibility mapping at central Zab basin, Iran: A comparison between analytical hierarchy process, frequency ratio and logistic regression models. CATENA, v. 115, 55-70, 2014.

SELBY, M. J. Hillslope: materials \& processes, New York, 1993.

SOUZA, J. L.; et. al. Características pluviométricas representativas do tabuleiro costeiro de Alagoas, período 1972-1996, 1998, Brasília. In: Anais... Brasília: VII CBM, 1998. p.1-5.

TORRES, F. S. M. Carta de suscetibilidade a movimentos de massa e erosão. 2014. 106 f. Dissertação (Mestrado em Engenharia Civil) - Universidade Federal de Pernambuco, Recife, 2014.

TRAN L. K. CG.; et al. Environmental assessment fuzzy decision analysis for integrated environmental vulnerability of the mid-atlantic region. Environ Manag. v. 29, 845-859, 2002.

VALERIANO, M.M.; CARVALHO JÚNIOR, O. A. Geoprocessamento de modelos digitais de elevação para mapeamento da curvatura horizontal em microbacias. Revista Brasileira de Geomorfologia. v. 1, 1729, 2003. 